Esta revista forma parte del acervo de la Biblioteca Jurídica Virtual del Instituto de Investigaciones Jurídicas de la UNAM

\title{
El interés superior del niño
}

\author{
The Best Interest of the Child
}

\section{Soledad TORRECUADRADA GARCÍA-LOZANO}

SUMARIO: I. Introducción. II. Interpretación del interés superior del niño. III. Bibliografía.

* Doctora en Derecho por la Universidad Autónoma de Madrid (España), donde se desempeña como profesora titular de Universidad en Derecho Internacional Público y Relaciones Internacionales desde 2000, acreditada a Catedrática de Universidad en esta disciplina por Resolución del Ministerio de Educación, Cultura y Deporte de España del 4 de julio de 2012. Tiene tres tramos de investigación evaluados positivamente por el mismo Ministerio. 
RESUMEN: El interés superior del niño es un principio básico en los derechos del niño. La Convención de Naciones Unidas de 1989 sobre los Derechos del Niño lo establece como derecho subjetivo de los menores de edad y como principio interpretativo de cuantas medidas potencialmente pudieran afectar directa o indirectamente a los niños. Más allá de lo establecido por la Convención, observamos que el principio del interés superior del menor es el motivo que inspira el mismo texto convencional, así como cualesquiera otras medidas protectoras de quienes aún no han alcanzado la mayoría de edad. Sin embargo, no se trata de un principio desprovisto de sombras que, como todos los que contemplan un margen de discrecionalidad, puede conducir a soluciones cuando menos discutibles.

Palabras clave: interés superior del menor, derechos del niño, derecho a ser escuchado, Convención de los Derechos del niño, principio interpretativo.

ABSTRACT: The best interest of the child is the basic principle in the child's rights. The 1989 UN Convention about child's rights established it as a subjective right for a minor and as an interpretative principle for every single measure who could affect them directly or indirectly. Beyond the established in the convention we can see that the best interest of the child is the reason who inspire the conventional text, so as every other measure about a minor. However, it is not a principle without dark shades, who gives the judge a margin of decision and could lead to some questionable solutions.

Key words: the best interest of the child, children rights, earing right, Children rights convention, interpretation principle.

RESUMÉ: L'intérêt supérieur de l'enfant est un principe fondamental dans les droits de l'enfant. La Convention des Nations Unies de 1989 sur les droits de l'enfance l'établi comme un droit subjectif pour les enfants et comme un principe interprétatif des mesures qui pourraient atteindre direct ou indirectement les enfants. Au-delà de l'établi par la Convention, on peut observer que l'intérêt supérieur de l'enfant est un motif qui inspire le même texte constitutionnel, comme toute autre mesure protectrice pour l'enfance. Cependant, ce n'est pas un principe sans nuances car il permet une marge qui a pu conduire à des solutions discutables.

Mots-clés: l'intérêt supérieur de l'enfant, droits de l'enfant, droit d'être entendu, Convention relative aux droits de l'enfance, principle interpretatif. 


\section{INTRODUCCIÓN}

El interés superior del menor se tuvo en cuenta ya en el derecho de familia en la sentencia Blissets, a finales del siglo XVIII (1774), que afirmaba "if the parties are disagreed, the Court will do what shall apear best for the child", 1 por lo que no se puede decir que resulte un principio novedoso. A pesar de ello, la Convención de Naciones Unidas sobre los Derechos del Niño² (en adelante, la Convención) ha supuesto un importante avance en lo que a su conceptualización y ámbito de aplicación se refiere. Así ha proclamado su doble naturaleza como derecho subjetivo y como principio y generalizado su aplicación a ámbitos materiales distintos de aquel que le vio nacer y en cuyo seno se ha desarrollado.

Desde una perspectiva internacional, la evolución del principio ha sido doble: por una parte, del mismo modo que en los derechos internos, se incorporó en tratados internacionales relativos al derecho de familia, en el que nació y se desarrolló hasta la entrada en vigor de la Convención; por otra, algunos textos de naturaleza recomendatoria se referían al interés del niño de forma más amplia. Entre los primeros (tratados internacionales sobre derecho de familia) se encuentran los textos convencionales materialmente sectoriales con los que se pretendía aportar respuestas transnacionales claras a cuestiones internas como la adopción internacional, ${ }^{3}$ o la concienciación acerca de la necesidad de regular cuestiones acerca de las

1 Véase en 98, Eng. Rep. 899 (K.B. 1774) (Mansfield, C. J.), citado entre otros por R. Laing Klaff, “The Tender Years Doctrine: A Defense”, en California Law Review, vol. 70-2, 1988, pp. 335-372

2 El término "niño" y "niños" se utiliza como genérico a lo largo de este trabajo, es decir, como niño y niña, niños y niñas.

3 Según el Convenio sobre la competencia de autoridades, ley aplicable y reconocimiento de decisiones en materia de adopción, de 1965, «las autoridades a que se refiere el párrafo primero del artículo 3 sólo constituirán la adopción si responde al interés del menor» (el Convenio puede consultarse en: http://www.hcch.net/upload/conventions/txt13es.pdf). Véase por todos la interesante contribución respecto de la aplicación del Principio del interés superior del menor en este ámbito concreto, González Sánchez, N. y Rodríguez Jiménez, S., "Capítulo tercero: El interés superior del menor y la adopción internacional de menores", en González Martín, N. y Rodríguez Jiménez, S., El interés superior del menor en el marco de la adopción y el tráfico internacional. Contexto Mexicano, México, UNAM, Instituto de Investigaciones Jurídicas, 2011, pp. 105 y ss. 
Esta revista forma parte del acervo de la Biblioteca Jurídica Virtual del Instituto de Investigaciones Jurídicas de la UNAM www.juridicas.unam.mx

cuales hasta entonces no existía acuerdo, como la edad mínima para contraer matrimonio ${ }^{4}$ o la discriminación contra la mujer. ${ }^{5}$

En relación con el segundo de los aspectos recién indicados, la Convención sobre el consentimiento para el matrimonio, la edad mínima para contraer matrimonio y el registro de los matrimonio establece (en su artículo segundo) la obligación estatal de fijar una edad mínima para contraer matrimonio, salvo dispensa de la autoridad competente, de nuevo "en interés de los contrayentes", que no es lo mismo que el interés del menor, puesto que no se trata de regular los matrimonios entre menores, sino de permitir que un menor de edad lo contraiga. Como las partes en el texto recién indicado no lograron alcanzar un acuerdo acerca de la edad mínima para contraer matrimonio y con el propósito de evitar disparidades en este punto por parte de las autoridades estatales, la Asamblea General de las Naciones Unidas adoptó la Recomendación sobre el consentimiento para el matrimonio, la edad mínima para contraer matrimonio y el registro de los matrimonios, en la que ese límite se establecía en los quince años. A pesar de ello, en la actualidad carecemos de una edad mínima para contraer matrimonio por dos motivos: el primero, porque no se pudo evitar en la Recomendación referida la reiteración de la salvedad contenida en la Convención que permite la celebración por debajo de esa edad si se aprecia que es en interés de los contrayentes $;{ }^{6}$ el segundo, debido a que la fijación

4 El texto de la Convención sobre el consentimiento para el matrimonio, la edad mínima para contraer matrimonio y el registro de los matrimonios puede descargarse en: http: / / www. ohchr.org/SP/ProfessionalInterest/Pages / MinimumAgeForMarriage. aspx.

5 La Convención sobre la Eliminación de Todas las Formas de Discriminación contra la Mujer es un tratado internacional adoptado el 18 de diciembre de 1979 por la Asamblea General de Naciones Unidas en la Resolución 34/180 y que cuenta en la actualidad con 188 Estados partes, véase http://daccess-dds-ny.un.org/doc/RESOLUTION/GEN/NRO/385/09/ $I M G / N R 038509$.pdf? OpenElement. El artículo 5o. de este texto convencional establece la obligación estatal de adoptar cuantas medidas resulten precisas para "b) Garantizar que la educación familiar incluya una comprensión adecuada de la maternidad como función social y el reconocimiento de la responsabilidad común de hombres y mujeres en cuanto a la educación y al desarrollo de sus hijos, en la inteligencia de que el interés de los hijos constituirá la consideración primordial en todos los casos”, proclamándose también la igualdad de derechos de los progenitores, en relación con los hijos, su interés se eleva como una "consideración primordial”.

6 La Recomendación es un anexo de la resolución 2018 (XX), de 1 de noviembre de 1965, en http://daccess-dds-ny.un.org/doc/RESOLUTION/GEN/NRO/221/56/IMG/NRO22156.pdf? OpenElement. 
Esta revista forma parte del acervo de la Biblioteca Jurídica Virtual del Instituto de Investigaciones Jurídicas de la UNAM

de los quince años como edad mínima se incorpora en un instrumento de naturaleza recomendatoria y no jurídicamente obligatoria para los Estados.

En la segunda línea antes indicada (los textos de naturaleza recomendatoria referidos al interés del niño de forma más amplia) se ubica la Declaración de Ginebra, adoptada el 26 de septiembre de 1924 por la Sociedad de Naciones cuyo preámbulo afirma que "l'humanité doit donner à l'enfant ce qu'elle a de meilleur", ${ }^{7}$ y treinta cinco años más tarde (en 1959) la Asamblea General de Naciones Unidas proclamaba en el Principio Séptimo de la Declaración sobre los Derechos del Niño, que su interés superior "debe ser un principio rector de quienes tienen la responsabilidad de su educación y orientación: dicha responsabilidad incumbe, en primer término, a sus padres". ${ }^{8}$ Con esta Declaración, aprobada tres décadas antes que la Convención, se inicia la ampliación del ámbito material que generalizará la Convención y lo hace estableciendo el deber primordial de garantía a los padres, sin excluir a otros agentes de estas responsabilidades.

La Convención de 1989 supone el punto álgido en el desarrollo del interés superior del niño, al incorporarlo como derecho subjetivo de los menores y como principio general inspirador y fundamental de los derechos del niño en su artículo tercero. ${ }^{9}$ Sin embargo, pese a la relevancia de este texto convencional, la entrada en vigor de este tratado internacional, lejos de ser la meta de este camino en la protección de los derechos de los menores, se ha transformado en el inicio de una nueva senda, ha resultado el

7 El texto de la Declaración puede consultarse en: http://xn--derechosdelnio-2nb.com/de claracion-de-ginebra.html.

8 Es la Resolución 1386 (XIV) de la Asamblea General, de 20 de noviembre de 1959. En este mismo sentido, el artículo quinto de la Declaración sobre los principios sociales y jurídicos relativos a la protección y el bienestar de los niños, con particular referencia a la adopción y colocación en hogares de guarda, en los planos nacional e internacional (adoptada el 3 de diciembre de 1986 como anexo a la Resolución 41/85 de la Asamblea General) proclama, de nuevo, en relación con el derecho de familia que: "En todas las cuestiones relativas al cuidado de un niño por personas distintas de sus propios padres, los intereses del niño, en particular su necesidad de recibir afecto y su derecho a la seguridad y al cuidado continuado, deben ser la consideración fundamental”.

9 Texto normativo adoptado el 20 de noviembre de 1989, cuyo contenido puede consultarse en https://www.unicef.es/sites/www.unicef.es/files/CDN_06.pdf. Posteriormente se incorpora también en el artículo 24.2 de la Carta de Derechos Fundamentales de la Unión Europea, que tras la entrada en vigor del Tratado de Lisboa el 1o. de noviembre de 2009 es derecho originario de esta organización internacional. 
Esta revista forma parte del acervo de la Biblioteca Jurídica Virtual del Instituto de Investigaciones Jurídicas de la UNAM

inicio de uno nuevo. Ello se debe a dos razones: una, que desde entonces se han adoptado actos jurídicos que realizan aportes a aquel, como la Declaración y el Programa de Acción de Viena de 1993, que además de reiterar su importancia, indica los grupos de niños en situación de mayor vulnerabilidad en los que los Estados deberían centrar su acción legislativa de modo prioritario; $;^{10}$ dos, a los avances que la interpretación jurisprudencial tanto internacional como interna ha producido en él, con la inestimable ayuda en este empeño de las observaciones generales del Comité en los que concreta el alcance de los derechos proclamados.

A pesar del optimismo que puede resultar de lo escrito hasta aquí, no podemos olvidar que el derecho, en sí mismo, es un instrumento claramente insuficiente para cambiar la realidad. Cuando leemos el informe del experto independiente de las Naciones Unidas para el estudio de la violencia contra los niños, ${ }^{11}$ comprobamos que esta lacra adopta variadas formas, física, sexual o psicológica. ${ }^{12}$ La información de Naciones Unidas acerca del crecimiento de niños en cárceles bolivianas, en las que sus progenitoras cumplen condena, nos muestra claramente que estamos lejos de erradicar comportamientos prohibidos por un tratado internacional en el que son parte 195 Estados, que se han comprometido voluntariamente en el cumplimiento de su contenido. ${ }^{13}$

Tampoco ayuda a identificar la realidad del compromiso estatal si leemos en los informes de la Organización Mundial de la Salud que:

Entre 100 y 140 millones de niñas y mujeres en todo el mundo viven con las consecuencias de la mutilación genital femenina; en cada año, aproximadamente 3,3 millones de niñas corren el riesgo de ser víctimas de mutilación genital femenina;

10 Véase http://www.ohchr.org/Documents / Events/OHCHR20/VDPA_booklet_Spanish.pdf.

11 Es el informe de 29 de agosto de 2006, doc. A/61/299, puede verse en: http: / / daccessdds-ny.un.org/doc/UNDOC/GEN/N06/491/05/PDF/N0649105.pdf?OpenElement.

12 Para profundizar sobre el marco teórico relativo a la violencia contra los niños, véase por todos: Macías Vázquez, M. C. et al., Marco teórico conceptual: violencia contra niños, niñas y adolescentes, México, UNAM, Instituto de Investigaciones Jurídicas, 2013.

13 Es cierto que la manifestación del consentimiento de no pocos Estados (nada menos que 72) van acompañados de declaraciones, reservas o incluso objeciones a las reservas. En el caso de España, expresa su desacuerdo, principalmente, con el establecimiento de quince años para el reclutamiento de menores al ejército. Edad que luego se eleva a los 18 en el Protocolo facultativo celebrado con este propósito. 
y en los 28 países acerca de los cuales existen datos nacionales sobre la prevalencia (27 países de África y Yemen), más de 101 millones de niñas de 10 o más años de edad están viviendo con los efectos de la mutilación genital femenina. ${ }^{14}$

O incluso la normalidad con la que se observa el maltrato infantil en tanto que medida correctora de comportamientos, que según los datos de la misma organización produjeron la nada desdeñable cifra de 31,000 defunciones de niños menores de quince años en 2002. ${ }^{15}$

La realidad que se vislumbra en el párrafo anterior ilustra abiertamente que aún quedan retos por enfrentar, evidenciados, por ejemplo algunas de las recientes decisiones del Comité Europeo de Derechos Sociales contra Checoslovaquia, Bélgica, Irlanda y Francia, en 2015 cuyas respectivas legislaciones carecían de una prohibición suficientemente clara del castigo físico contra los niños. ${ }^{16}$ Estas decisiones revelan igualmente la laxitud con la que se aprecian los derechos del niño, de ahí la campaña "las manos deberían proteger, no pegar", ${ }^{17}$ lanzada por ese mismo Comité. Los datos indicados subrayan la hipocresía de los Estados que con una mano se comprometen a unos estándares mínimos de protección de los derechos humanos, mientras con la otra omiten adoptar internas eficaces que propicien el cumplimiento de sus objetivos.

En todo caso, estas informaciones y otras muchas que omitimos aquí muestran que aún quedan múltiples tareas por realizar para alcanzar una protección razonable de los derechos de los niños, que sólo podrá fundarse en el interés superior del niño. Pese a lo recién indicado hemos de valorar muy positivamente los avances producidos hasta el momento, así como la relevancia de la Convención y de sus protocolos facultativos que se adoptaron en el año 2000 relativos a la participación de niños en los conflictos ar-

14 Véase la hoja informativa de la Organización Mundial de la Salud sobre la mutilación genital femenina en: http: / / apps.who.int/iris/bitstream/10665/98838/1/WHO_RHR_12.41_ spa.pdf?ua $=1$.

15 Véase el informe de la OMS titulado "Prevención del maltrato infantil: qué hacer y cómo obtener evidencias", OMS, 2009, puede consultarse en: http: / /whqlibdoc. who.int/publi cations/2009/9789243594361_spa.pdf.

16 Son las decisiones de 20 de enero y 4 de marzo respectivamente, ver en: http: / / hudoc. esc.coe.int $/$ fre? $=$ cc-96-2015-dmerits-eng.

17 Véase http://www.coe.int/t/dg3/children/corporalpunishment/pdf/SaatchiFra1.pdf. 
Esta revista forma parte del acervo de la Biblioteca Jurídica Virtual del Instituto de Investigaciones Jurídicas de la UNAM

mados ${ }^{18} \mathrm{y}$ a la venta de niños, prostitución infantil y la utilización de niños en la pornografía. ${ }^{19}$ Estos dos últimos textos se concibieron con la idea de preservar el interés superior del menor y establecen en su preámbulo que se adoptaron con la convicción de que el interés superior del menor "ha de ser una consideración primordial en todas las medidas que se adopten en relación con los niños". ${ }^{20}$ Las páginas que siguen se centran en el análisis de este principio, en su concepto, luces y sombras, así como en los criterios a tener en cuenta para su correcta aplicación y las consecuencias de la misma.

\section{INTERPRETACIÓN DEL INTERÉS SUPERIOR DEL NIÑO}

Para conocer el derecho y el principio del interés superior del menor tenemos previamente que identificar sus perfiles, con este propósito en un primer lugar nos detendremos en su caracterización, pasando después a abordar la identificación de aquellos que habrán de conocerlo en profundidad, al corresponderles su aplicación, para centrarnos posteriormente en los criterios determinantes que han de observarse con el propósito de visualizar las medidas que mejor se acomodan a este derecho y principio interpretativo fundamental; todo ello con la finalidad de concluir apuntando los posibles riesgos que derivan de su aplicación.

\section{Caracterización del interés superior del niño}

El interés superior del menor es un derecho subjetivo de los niños y un principio inspirador y fundamental de los derechos de los que son titulares, que posee un propósito protector de "los menores debido a su especial vulnerabilidad a causa de la imposibilidad que tiene de dirigir su vida con

18 Protocolo que cuenta con 159 Estados Parte, véase la relación en https: / treaties.un.org / Pages $/$ ViewDetails.aspx?src $=$ TREATY\&mtdsg_no $=I V-11$-b\&chapter $=4 \&$ lang $=e n$.

19 Protocolo que reúne a 169 Estados partes, cuya relación puede verse en https: / treaties. un.org/Pages $/$ ViewDetails.aspx?src=TREATY\&mtdsg_no $=I V-11$-c\&chapter=4\&lang =en .

20 Véase la Resolución 54/263, de la Asamblea General de 25 de mayo de 2000, véase http: / / daccess-dds-ny.un.org/doc/UNDOC/GEN/NO0/625/70/PDF/N0062570.pdf?OpenEle ment. 
Esta revista forma parte del acervo de la Biblioteca Jurídica Virtual del Instituto de Investigaciones Jurídicas de la UNAM

total autonomía”. ${ }^{21}$ Este principio se incorpora puntualmente a lo largo de la Convención ${ }^{22}$ y con carácter general en su artículo tercero cuyo apartado primero establece lo siguiente:

En todas las medidas concernientes a los niños que tomen las instituciones públicas o privadas de bienestar social, los tribunales, las autoridades administrativas o los órganos legislativos, una consideración primordial a que se atenderá será el interés superior del niño.

En estas breves líneas se encuentra un apunte de la múltiple funcionalidad con la que se le caracteriza el principio que nos ocupa: inspiradora tanto de políticas como de legislación (nacionales o internacionales) susceptibles de afectar de algún modo a los menores de edad así como para quienes han de aplicarlas. Esto resulta evidente en lo que se refiere a la relación entre el ordenamiento internacional y los ordenamientos internos pues los Estados están jurídicamente obligados por los tratados en los que han consentido, cuyo cumplimiento ha de proveer el derecho interno $^{23}$ con independencia del ámbito material del que se trate, ya sea derecho civil (tutela, filiación, régimen de visitas u otros), derecho penal o laboral, entre otros. La naturaleza inspiradora del interés superior del niño

21 Rodríguez Llamas, S., "La atribución de la guarda y custodia en función del concreto y no abstracto interés superior del menor. Comentario a la STS núm. 679/2013, de 20 de noviembre (RJ 2013/7824), en Revista Boliviana de Derecho, núm. 19, enero de 2015, pp. 563 575. La idea transcrita se encuentra en la página 569.

22 Así como justificación para la separación del niño de sus progenitores (artículo 9.1) o de la privación del ambiente familiar (artículo 20.1), indica que la preocupación principal de los padres en la crianza y desarrollo del niño (artículo 18.1), se proclama como consideración primordial supuestos que afectan a niños privados de ambiente familiar (artículo 20.1), como en del sistema de adopción (artículo 21), en relación a niños que se encuentren privados de libertad (artículo 37.c), o a aquellos a quienes se les atribuye una infracción de normas penales (artículo 40.2.b)iii).

23 Véase en este sentido la Ley Orgánica 1/1996 modificada recientemente por Ley Orgánica $8 / 2015$, de 22 de julio, de modificación del sistema de protección a la infancia y a la adolescencia, publicada en el Boletín Oficial del Estado núm. 174, de 23 de julio de 2015, Sec. I, pág. 61872 y ss. en las que se justifica su adopción en la necesidad de reforzar este principio. También la Ley 26/2015, de 28 de julio, de modificación del sistema de protección a la infancia y la adolescencia, publicada en Boletín Oficial del Estado núm. 180, del 29 de julio de 2015, Sec. I, pp. 64545 y ss. justifica la adopción de las modificaciones introducidas en la Ley 1/1996 precisamente en el interés superior del niño. 
Esta revista forma parte del acervo de la Biblioteca Jurídica Virtual del Instituto de Investigaciones Jurídicas de la UNAM

es meridianamente clara, al ser el elemento sobre el que se construyen sus derechos, si no fuera porque los menores de edad gozan de un interés social fundamental carecerían de una regulación específica protectora de sus derechos (desde esta perspectiva, es el motivo de la existencia de la misma la Convención que lo proclama). Un ejemplo de esta naturaleza son los protocolos de la Convención.

Es un principio jurídico interpretativo fundamental, ${ }^{24}$ pues toda norma que haya de aplicarse en una situación que afecte real o potencialmente a un menor ha de interpretarse a la luz de su interés superior, lo que nos conduce a que el órgano encargado de la aplicación de una norma ha de considerar, de entre todas las interpretaciones posibles, aquella que nos pueda aportar una norma aplicable a un caso que afecta directa o indirectamente a un niño, hemos de considerar aquella que satisfaga en mayor medida el interés de este último.

Por su parte, la profesora Carmona Luque lo caracteriza como "un principio esencial; interdependiente respecto al conjunto de derechos proclamados en la Convención y de manera subrayada, respecto a los demás principios generales de ésta; exclusivo del niño; armonizador; no absoluto; indeterminado; y dinámico". ${ }^{25}$ De esta relación nos interesan de modo particular los dos rasgos apuntados en último lugar.

El principio de interés superior del menor es un concepto jurídicamente indeterminado, de muy difícil definición concreta única y útil, aplicable a todos los casos en presencia, debido a la heterogeneidad de sus titulares, pues igual se puede predicar de un titular individual (un niño) o colectivo más o menos amplio (un grupo de niños o todos ellos). Por lo demás, ningún niño ni grupo de ellos es igual a otro, bien al contrario, tienen necesidades distintas en función de las circunstancias que a cada uno le rodean, por ejemplo un niño huérfano, discapacitado, refugiado, un niño soldado o

24 Este es uno de los tres rasgos característicos de los que dota el Comité de Naciones Unidas sobre los Derechos del niño a este principio, junto que es un derecho sustantivo y una norma de procedimiento. Ver en este sentido la Observación General núm. 14 sobre el derecho del niño a que su interés superior sea una consideración primordial (artículo 3o., párrafo 1), aprobada por el Comité en su 62o. periodo de sesiones (de 14 de enero a 1 de febrero de 2013), es el Documento CRC/C/GC/14, que puede consultarse en http://www.unicef.cl/ web/informes/derechos_nino/14.pdf.

25 Véase Carmona Luque, M. R., La Convención sobre los Derechos del Niño. Instrumento de progresividad en el Derecho Internacional de los Derechos Humanos, Madrid, Dykinson, 2011, p. 104. 
Esta revista forma parte del acervo de la Biblioteca Jurídica Virtual del Instituto de Investigaciones Jurídicas de la UNAM

víctima de un conflicto armado, un indígena, una víctima de abusos sexuales o escolares, hijos de padres separados pacíficamente o no.

La situación recién indicada se complica aún más porque las diferencias de edad y madurez de los niños requieren respuestas variadas y también porque podemos encontrarnos con quienes sobreviven en más de una de las situaciones anteriores, o con factores de afectación al desarrollo del niño mutables en circunstancias que pueden parecernos objetivamente similares, la evolución particular del menor (nivel de desarrollo emocional, autonomía...) o de su mismo entorno social.

Por todo ello, no existe una única fórmula para resolver del modo que más pueda beneficiar en mayor medida el interés de los menores, por lo que precisa interpretaciones in concreto, como dice el profesor Pocar: "Las soluciones no pueden ser neutras, bien al contrario, han de adaptarse al contexto y proporcionar protección al más débil”26 o, en palabras de $\mathrm{M}$. Vargas Gómez-Urrutia, "es precisamente la aplicación in concreto al caso, lo que permite dilucidar su contenido". ${ }^{27}$

De lo anterior se desprende que el interés superior del menor es un derecho y un principio con contenido y perfiles complicados de visualizar en abstracto. La diversidad de las medidas que su aplicación puede implicar provoca que no sea tan relevante su concepto en sí mismo como la finalidad que persigue y los criterios que han de guiar al órgano encargado de su aplicación. Una consecuencia de esta indeterminación es el dinamismo característico del principio, que permite su adaptabilidad a las distintas situaciones en presencia.

Si dotásemos de un contenido concreto al interés superior del menor estaríamos vaciándolo de significado e impediríamos la proyección de su aplicación. ${ }^{28}$ Sin embargo, de ese necesario dinamismo deriva su principal problema: el margen de discrecionalidad del encargado de su aplicación. Es un problema, en la medida en que quien ha de aplicarlo puede no resistir a la tentación de decidir teniendo en cuenta sus convicciones, aportando la

26 Pocar, F., "La protection de la partie faible en Droit International Privé", RCADI, 188 (1984)-V, pp. 341-417.

27 Vargas Gómez-Urrutia, M., La protección internacional de los derechos del niño, Secretaría de Cultura-Gobierno de Jalisco, 1999, p. 95. También en "El interés del menor como principio inspirador del derecho convencional de la Conferencia de La Haya de Derecho Internacional Privado" en http://e-spacio.uned.es/fez/eserv/bibliuned:DptoDEMP-FDER-DIP-Mvargas18/ Vargas_Marina_1999_ART_RDP_menoresHCCH.pdf, p. 107.

28 Véase Carmona Luque, M. R., La Convención sobre los Derechos del Niño..., cit, p. 110. 
Esta revista forma parte del acervo de la Biblioteca Jurídica Virtual del Instituto de Investigaciones Jurídicas de la UNAM www.juridicas.unam.mx

solución que, desde esa perspectiva y no la del niño en cuestión, le resultaría más conveniente.

Pensemos en el caso Atala, ${ }^{29}$ cuyo origen se encontraba en la separación de una pareja con dos hijas. La esposa comienza a compartir su vida con otra mujer, por lo que el marido interpone una demanda solicitando la custodia de las menores argumentando que “«el desarrollo físico y emocional [de las niñas estaría] en serio peligro» de continuar bajo el cuidado de su madre", debido a que su "su nueva opción de vida sexual sumada a una convivencia lésbica con otra mujer" incapacitaban a la madre para ejercer la custodia de las menores. ${ }^{30}$ La Corte Suprema chilena, con fundamento en el interés superior del menor, acogió los argumentos del padre, concediéndole la custodia de las menores. ${ }^{31}$

Por su parte, la Corte Interamericana de Derechos Humanos consideró la decisión de los jueces chilenos contraria a los derechos humanos tanto de la madre como de las hijas. Además subrayó que:

$\mathrm{Al}$ ser, en abstracto, el "interés superior del niño" un fin legítimo, la sola referencia al mismo sin probar, en concreto, los riesgos o daños que podrían conllevar la orientación sexual de la madre para las niñas, no puede servir de medida idónea para la restricción de un derecho protegido como el de poder ejercer todos los derechos humanos sin discriminación alguna por la orientación sexual de la persona. ${ }^{32}$

La decisión de la Corte Interamericana aclara dos cuestiones: la necesidad de motivar en cada caso en el que se alegue el interés superior del niño, la decisión que se fundamenta en este principio. En este punto, ante los tribunales es frecuente la presentación de informes psicológicos de los niños afectados. En otros es la mera lógica la que puede indicarnos la mejor de las

29 Se trata de la Sentencia de la Corte Interamericana de Derechos Humanos, de 24 de febrero de 2012, en el asunto Atala Riffo y niñas contra Chile. La sentencia puede leerse en: http: / / corteidh.or.cr/docs/casos/articulos/seriec_239_esp.pdf

30 El texto transcrito se encuentra en el parágrafo 31 de la sentencia citada en la nota anterior. No es un argumento extraño en los tribunales españoles, pues fue igualmente defendido por el Juez Fernando Fermín Calamita, cuya parte sustantiva puede leerse en la Sentencia del Tribunal Supremo 1243/2009, de 30 de octubre de 2009, en la que se condena al juez indicado por un delito de prevaricación judicial.

31 Véase Parágrafo 57 de la Sentencia Atala.

32 Véase Parágrafo 110 de la Sentencia Atala. 
soluciones para los menores en cuestión, dado que los niños precisan para su seguridad del mantenimiento de dinámicas, rutinas y de su entorno afectivo, debería primarse la solución que mejor se adaptara a este criterio, salvo que evidentemente, sea este contexto el que afecta negativamente al niño.

La segunda de las cuestiones aludidas se centra en que no hay soluciones únicas para casos que nos puedan parecer objetivamente similares. Por ello, debe considerarse el principio del interés superior del menor y hacerlo "como un criterio de ponderación abierto y un principio necesario inspirador de todas las actuaciones relacionadas con el menor, tanto en el ámbito administrativo como judicial”. ${ }^{33}$

Esto lo podemos ilustrar con el mismo caso Atala, en el que la solución estaba fundada en el interés superior de las niñas en cuestión, pero si ubicásemos el mismo supuesto en una sociedad cerrada y conservadora que estigmatizara a las menores afectando su desarrollo físico y emocional ¿deberíamos mantener la misma solución? Desde mi punto de vista, la respuesta ha de ser negativa, pues si bien con ello estaríamos discriminando a la madre debido a su orientación sexual, hemos de considerar que nuestro objetivo es en este punto hacer prevalecer el interés de las niñas, y en el caso en presencia no podemos arriesgarnos a una afectación negativa en su desarrollo emocional.

Pues bien, pese a los riesgos, la discrecionalidad es necesaria para dotar de la necesaria adaptabilidad del principio a las circunstancias en presencia que pueden afectar a un menor o grupo de menores, pues como hemos podido comprobar, una solución puede estar fundamentada en el interés superior de un menor concreto y no resultar del todo adecuada al de otro.

\section{Los órganos que han de aplicar el interés superior del niño}

El órgano aplicador del interés superior del menor depende del plano en el que se encuentre la decisión, es decir, será el representante del Estado en una negociación internacional para la celebración del tratado internacional en el que se ha de incorporar la redacción más favorable al interés de los niños; el legislador si el principio actúa como inspirador de la legislación

33 Bartolomé Cenzano, J. C. de, "Sobre la interpretación del interés superior del menor y su trascendencia en el derecho positivo español”, Revista sobre la Infancia y la Adolescencia, núm. 3, septiembre de 2012, pp. 46-59. La transcripción del texto se encuentra en la p. 50. 
Esta revista forma parte del acervo de la Biblioteca Jurídica Virtual del Instituto de Investigaciones Jurídicas de la UNAM

que pueda afectar a los menores, o el órgano judicial o administrativo que haya de decidir en un caso concreto la aplicación de una norma que pueda afectar a menores, en cuyo caso, deberán interpretar la disposición en cuestión a la luz del principio del bien superior del menor.

Sin embargo, los aplicadores habituales de este principio son los padres de los niños, que habrán de adoptar todas las decisiones que pudieran afectarles orientados precisamente en atención a su interés superior, puesto que, tal y como establece el artículo 18 de la Convención: "Incumbirá a los padres o, en su caso, a los representantes legales la responsabilidad primordial de la crianza y el desarrollo del niño. Su preocupación fundamental será el interés superior del niño”.

Evidentemente, al decidir sobre estas cuestiones (educativas, de desarrollo físico, psicológico, emocional...) deberán hacerlo orientados por el que consideran el interés superior de su hijo. Sin embargo, hay que observar que aquí también se pueden diversificar las decisiones, dado que la heterogeneidad implica que una misma solución puede no beneficiar del mismo modo a todos los hijos, debiendo, como veíamos antes, adaptar ese interés a las características y necesidades concretas del niño al que pretendemos en cada momento aplicar el principio.

La variedad de potenciales aplicadores del interés superior del menor ilustra la multifuncionalidad de este principio, tanto horizontal como vertical, en el sentido de que nos ubicamos en escenarios distintos debido al plano en el que haya de considerarse. Así, serán los órganos encargados de la producción normativa o del diseño de políticas públicas aplicables al grupo en cuestión que podrá ser más amplio si es un contexto internacional, nacional o autonómico-local o se trata de un órgano encargado de la aplicación de las normas y políticas en cuestión.

También hemos de subrayar la diferencia que aportan los destinatarios de nuestra tarea, pues no es lo mismo plantear con carácter objetivo medidas que puedan afectar a un colectivo que pretende ser universal desde una perspectiva espacial (tratados internacionales) o regional, aunque puede resultar general por el objeto (dirigido a la infancia en general) o sectorial, si nos centramos en determinados grupos — los niños en riesgo de exclusión, por ejemplo- , que con un alcance estatal o autonómico, o a un caso particular en el que habrá que considerar de modo específico las circunstancias concretas que le rodean para poder determinar cuál es la aplicación que puede resultar más beneficiosa. 
Si nos planteamos la determinación de cuál es el interés superior en un caso concreto, lo que sería la aplicación individual, sería el órgano que estuviera resolviendo el asunto en el que ha de aplicarse de modo directo o como parámetro de interpretación (al interpretar la norma en cuestión a la luz del principio). Sin embargo, el órgano que ha de ponderar ese interés superior puede discrepar a la luz del desarrollo de los acontecimientos respecto de lo decidido anteriormente por otro.

Pensemos en un caso que nos proporciona la jurisprudencia española. Se trata de un asunto resuelto por la Audiencia Provincial de Las Palmas de Gran Canaria, en el que determinó la separación de dos hermanas estableciendo que la guardia y custodia de dos hermanas fuera para cada uno de los progenitores. Ello se debía a que el padre había iniciado un procedimiento de impugnación de la filiación paterna respecto de una de ellas (aquella cuya guardia y custodia se atribuye a la madre), fruto de la cual se determinó que el recurrente no era padre biológico de la menor. Consideraba la Audiencia Provincial que el interés superior del menor se materializaba en la asignación a la madre de la patria potestad, la guardia y la custodia de la afectada, sin ponderar la estabilidad emocional de ambas niñas, así como la inestabilidad de la madre, pues inicialmente se había concedido la custodia de la otra hija a la madre y había tenido que modificarse pues no aceptaba que la hija se relacionase con el padre. Respecto de la otra menor que no es hija biológica del recurrente, el Tribunal Supremo decidió que la legislación española no impide la posibilidad de proteger también su interés, pues las dos hermanas:

Han convivido juntas desde el nacimiento de la primera, tanto bajo la guardia y custodia de la recurrente como de la del recurrido, con el que han mantenido unas buenas relaciones, como dice la sentencia, y que vuelven a estar juntas en una situación estable y adaptada a la unidad familiar formada por el Sr. Julián y su nueva esposa, con la que tiene un hijo de corta edad, teniendo como tiene éste capacidad para asumir el cuidado de las menores, como se recoge en la sentencia del Juez de Primera instancia, sin perjuicio de que la medida que se acuerda pueda ser revisada cuando se acredite el cambio de la situación de hecho y las nuevas circunstancias que permitan otra distinta que conjugue todos los intereses en juego. ${ }^{34}$

34 El texto transcrito se encuentra en el Fundamento Jurídico Tercero de la Sentencia del Tribunal Supremo núm. 679/2013, del 20 de noviembre. 
Esta revista forma parte del acervo de la Biblioteca Jurídica Virtual del Instituto de Investigaciones Jurídicas de la UNAM www.juridicas.unam. $\mathrm{mx}$

En consecuencia con lo anterior, es el órgano encargado de la aplicación de las normas a un caso concreto, el que ha de ponderar con cuál de las interpretaciones normativas se protege o se beneficia en mayor medida el interés del menor al que va a aplicarse su decisión. Ello no quiere decir que sea el único que pueda considerar este interés ya que, según el Tribunal Supremo, la decisión inicialmente adoptada podrá alterarse "mediante el procedimiento de modificación de medidas, siempre que las nuevas circunstancias sean favorables al interés del menor". ${ }^{35}$

Del mismo modo, el Alto Tribunal inadmitió un recurso de casación reiterando la doctrina asentada, según la cual:

La revisión en casación de los casos de guarda y custodia solo puede realizarse si el juez a quo ha aplicado incorrectamente el principio de protección del interés del menor a la vista de los hechos probados en la sentencia que se recurre. ${ }^{36}$

En este mismo sentido reitera el Tribunal Supremo que el recurso de casación no es una vía plausible para:

Cuestionar la valoración de la prueba ni de atacar los hechos, sino de revisar la valoración que de este interés hace la sentencia a partir de los hechos que han quedado probados. La determinación del mayor beneficio para el menor, al tratarse de la valoración de una calificación jurídica, puede ser, en definitiva, objeto de una revisión conceptual en casación. ${ }^{37}$

Y ello con el propósito de que el régimen de custodia resulte acorde al principio del interés superior del niño.

Así, los tribunales españoles entienden que la conflictividad entre los progenitores de un menor cuya custodia está en proceso de atribución es neutra, no puede valorarse como un elemento determinante en sí mismo para decidir la guardia y custodia compartida "solo se convierten en rele-

35 El texto indicado se encuentra en el Fundamento Jurídico Tercero in fine de la Sentencia del Tribunal Supremo núm. 578/2001, del 21 de julio.

36 Véase el Fundamento Jurídico Segundo del Auto de la Sala Civil del Tribunal Supremo del 2 de julio de 2013, en el que se inadmite un recurso de casación interpuesto contra la Sentencia de la Audiencia Provincial de Madrid del 20 de julio de 2012.

37 Fundamento Jurídico Cuarto de la Sentencia del Tribunal Supremo núm. 384/2005, del 23 de mayo. 
vantes cuando afecten, perjudicándolo, el interés del menor" ${ }^{38}$ Por tanto, esa neutralidad se mantiene si lo que se pretende es la alteración de la decisión inicial en este punto.

Como decíamos al inicio de este epígrafe, quienes han de velar día a día por el interés superior del menor son los padres o los titulares de su custodia. Desde una perspectiva internacional, el Estado debe responder internacionalmente de la observancia del principio, pues ha de defender sus actuaciones en lo que se refiere al cumplimiento de las obligaciones derivadas del Convenio ante el Comité de Naciones Unidas sobre los Derechos del Niño (en adelante, el Comité) que se crea en aplicación de su artículo 43. Ello supone la necesidad de que el ordenamiento nacional contenga medidas suficientes que permitan el cumplimiento de las obligaciones en presencia de quienes son los primeros responsables de ello.

\section{Criterios aplicables para determinar el interés superior del niño}

Del mismo modo que carecemos de una definición acerca del interés superior del menor, tampoco contamos con criterios aplicables con carácter general para determinarlo, pues ni los textos internacionales ni los nacionales (el Código Civil Español o la Ley Orgánica de Protección del Menor) los establecen de forma taxativa.

En este sentido, la Observación General del Comité sobre el derecho del niño a que su interés superior sea una consideración primordial, ${ }^{39}$ aporta una relación abierta de elementos a considerar cuando haya de identificarse el bien superior del menor, en concreto los siete siguientes: la opinión del niño, su identidad, ${ }^{40}$ la preservación del entorno familiar y mantenimiento de las relaciones, cuidado, protección y seguridad del niño, situación de

38 Véase el Fundamento Jurídico Cuarto de la Sentencia del Tribunal Supremo, núm. $571 / 2011$, del 22 de julio.

39 Se trata de la Observación General de 29 de mayo de 2013, Doc. CRC/C/GC/14, cuya referencia completa puede verse supra en nota núm. 24.

40 La Ley Orgánica 8/2015, citada supra en nota núm. 23 incorpora "La preservación de la identidad, cultura, religión, convicciones, orientación e identidad sexual o idioma del menor, así como la no discriminación del mismo por éstas o cualesquiera otras condiciones, incluida la discapacidad, garantizando el desarrollo armónico de su personalidad" (artículo 2.2.d), entre los criterios generales que han de tenerse en cuenta (entre otros) a la hora de considerar el interés superior del menor. 
Esta revista forma parte del acervo de la Biblioteca Jurídica Virtual del Instituto de Investigaciones Jurídicas de la UNAM

vulnerabilidad, el derecho del niño a la salud y a la educación. Esta evaluación, por supuesto, desde la garantía estatal del "pleno respeto de su derecho intrínseco a la vida, la supervivencia y el desarrollo". ${ }^{41}$

Por su parte, en España, la Ley Orgánica de Protección Jurídica del Menor (tal y como ha quedado redactada tras la modificación del sistema de protección a la infancia y a la adolescencia) distingue (en su artículo segundo) entre criterios y elementos a considerar para determinar cuál es el interés superior del menor en un caso concreto. Hay que tener en cuenta los criterios y elementos que se indican siempre en función del escenario que se nos presenta. Así, la ponderación de los intereses en presencia será distinta en función de la posición que ocupe el menor: que en un caso concreto podrá ser la víctima o el autor de un delito. Junto con ello habrá que considerar la edad del niño, pues un adolescente expresará una opinión formada, mientras que si se encuentra en los primeros años de su vida poseerá inevitablemente menor relevancia que el anterior, ello sin olvidar que la edad es un indicativo de su madurez, que es lo realmente importante cuando de escuchar ${ }^{42}$ (que no solamente oír) al menor se trata. Lo que hay que determinar en este punto es la capacidad de transmitir ideas propias responsablemente formadas y no inducidas mediante algunos mecanismos, entre los que no podemos descartar el miedo del niño a las consecuencias de su manifestación de voluntad en aquellos a quienes pueda afectar.

La Defensora del Pueblo de España va más allá en cuanto a la relevancia de la opinión expresada por él al indicar que si la decisión del juez no se

41 Id., nota 24, parágrafo 52, p. 13.

42 La Ley Orgánica de modificación del sistema de protección a la infancia y a la adolescencia considera la edad y madurez del menor con una doble funcionalidad: 1) como criterio general conforme a los cuales se ha de interpretar y aplicar su interés superior («b) La consideración de los deseos, sentimientos y opiniones del menor, así como su derecho a participar progresivamente, en función de su edad, madurez, desarrollo y evolución personal, en el proceso de determinación de su interés superior»); 2) como uno de los elementos de acuerdo con los que se han de ponderar los criterios generales que enumera en el artículo 2 (al señalar en el artículo 2.3. a) «la edad y madurez del menor»). Bien es cierto que el significado del criterio y del elemento son diversos, puesto que el primero se refiere al ejercicio por parte del niño de su derecho a ser escuchado en las cuestiones que de algún modo puedan afectarle (reiterado en el artículo 2.5. apartado a) y en el artículo 9), mientras el segundo es un criterio añadido y que no se refiere sólo al ejercicio de ese derecho, que tiene un alcance más amplio en cuanto a la medida a adoptar que se hace depender, de algún modo, de la edad física o psicológica del menor en cuestión. 
Esta revista forma parte del acervo de la Biblioteca Jurídica Virtual del Instituto de Investigaciones Jurídicas de la UNAM

acomodase a ella deberá ser consecuencia de motivos excepcionales, que se tendrán que motivar suficientemente. ${ }^{43}$

Un elemento controvertido a la hora de proceder a su evaluación es el relativo a la identidad cultural, concepto por el que según el Comité se entenderá el idioma, sexo, religión, cultura, personalidad... ${ }^{44}$ que reitera Ley Orgánica (artículo 2.2.d). Para evitar interpretaciones incorrectas de esta categoría, aquel órgano establece como límite de la identidad cultural el respeto a los derechos reconocidos en la Convención, ${ }^{45}$ además de aclarar que se tendrá en cuenta en la decisión sobre la familia adoptante, prefiriéndose a la que posea una identidad cultural más parecida al origen del menor.

El resto de los elementos quizá son de sentido común, la preservación del entorno del niño es fundamental, sabemos que necesitan rutinas cuyo mantenimiento les proporciona seguridad, de ahí que su continuidad sea relevante a la hora de conservar la estabilidad emocional. Por este motivo, la Convención establece su separación del núcleo familiar exclusivamente si viene aconsejado por el interés superior del menor (artículo 20.1). Por otra parte, en el caso de ruptura en la familia, la custodia ha de procurar incidir en la menor manera posible en las rutinas del pequeño y en todos los casos hay que procurar sostener una relación normalizada con ambos progenitores y sus familias en sentido amplio. Resulta más difícil el éxito de este intento cuando los padres no sólo están separados sino que habitan en distintos países o incluso continentes. ${ }^{46}$

En este punto, hemos de tener en cuenta la importancia del paso del tiempo. ${ }^{47} \mathrm{Si}$ bien los menores suelen caracterizarse por su gran capacidad de adaptación a circunstancias nuevas, para su propio equilibrio emocio-

43 El párrafo transcrito es de la defensora del pueblo Estudio sobre la escucha y el interés superior del menor. Revisión judicial de medidas de protección y procesos de familia, Madrid, mayo de 2014 , p. 34.

44 En los parágrafos 55-57, p. 14 de la Observación General núm. 14, citada en nota 24.

45 Ibidem. Parágrafo 57 indicado en nota supra.

46 Por este motivo, el Comité hace un llamamiento a la manifestación del consentimiento en obligarse de los Estados por los Convenios las Conferencias de La Haya de Derecho Internacional Privado que incorporan normas para resolver aspectos relevantes como la sustracción de menores, la adopción internacional o el reconocimiento y ejecución de sentencias en materia de obligaciones alimentarias, entre otros.

47 La Ley Orgánica de modificación del sistema de protección a la infancia y a la adolescencia, incorpora en el artículo 2.3.c) de la Ley Orgánica 1/1996 “[E]el irreversible transcur- 
Esta revista forma parte del acervo de la Biblioteca Jurídica Virtual del Instituto de Investigaciones Jurídicas de la UNAM www.juridicas.unam.mx

nal, no conviene alterar frecuentemente su modo de vida. Un elemento determinante es el transcurso del tiempo que tiende a fortalecer los lazos que les unen con el entorno próximo y a debilitar la relación con el más lejano, aunque sea el biológico. Ese transcurso fue determinante para decidir sobre el interés superior del menor en el caso Forneron e hija contra Argentina,${ }^{48}$ originado por un embarazo no comunicado al padre biológico y la entrega en adopción del bebé fruto de aquella relación a una familia, pese a la solicitud del padre de hacerse cargo de su hija. El procedimiento ante los órganos judiciales argentinos se dilató de tal modo que cuando llega a la Comisión interamericana de Derechos Humanos la menor ha cumplido ya los diez años. El transcurso del tiempo está sobradamente establecido que crea vínculos afectivos entre el menor y el entorno familiar que le rodea, sea biológico, de acogida o adoptivo, de modo que la dilación de plazos en sí misma puede fundamentar una decisión adversa al reclamante en este caso, en aras al interés superior del menor, aunque el interesado hubiera actuado con la diligencia debida. ${ }^{49}$

Por lo que se refiere al cuidado, protección y seguridad del niño, así como su derecho a la salud y a la educación, de nuevo hay que tener en cuenta las distintas necesidades que se tienen en función del grado de madurez, las circunstancias que lo rodeen o las amenazas que puedan afectarle. Por ejemplo, la práctica nos ilustra que las niñas están más expuestas al abuso sexual y los niños al reclutamiento para combatir en conflictos

so del tiempo en su desarrollo" como un elemento de ponderación de los criterios generales que apunta.

48 Es la Sentencia de la Corte Interamericana de Derechos Humanos de 27 de abril de 2012, en el asunto Fornerón e hija v. Argentina, que puede leerse íntegramente en http:// corteidh.or.cr/docs/casos/articulos/seriec_242_esp.pdf.

49 La argumentación resulta evidente y está plasmada tanto en la Resolución de la Corte Interamericana de Derechos Humanos de 2 de julio de 2011 en el asunto L.M. , medidas provisionales respecto de Paraguay, considerando 18, aunque previamente se había expresado del mismo modo la jurisprudencia del Tribunal Europeo de Derechos Humanos (ver la sentencia de 6 de abril de 2009 en el asunto Clemeno y otros c. Italia) así como el Comité sobre los Derechos del niño en su observación general núm. 7, párrafo 18, donde se afirma que las "situaciones que probablemente repercutan negativamente en los niños pequeños son... las situaciones en las que los niños experimentan relaciones interrumpidas (inclusive separaciones forzadas)", con lo que se subraya la evidencia de que extraer, aunque sea temporalmente, al niño del que es su entorno familiar habitual suele contravenir su interés superior, en la medida en que repercuten negativamente en su desarrollo emocional. 
armados, pero unos no están protegidos por razón de género de las amenazas que afectan a los otros. En este punto el Estado ha de adoptar las medidas necesarias para prevenir y reprimir los comportamientos que puedan afectar la seguridad del niño (entendido en genérico) y proporcionar los mejores medios sanitarios y educativos gratuitos posibles.

En cuanto a la situación de vulnerabilidad, lo único claro y decisivo es que han de adoptarse medidas de discriminación positiva, imprescindibles para alcanzar la igualdad de niños que parten de situaciones asimétricas, porque ¿cómo conseguir que niños que conforman un grupo vulnerable salgan de él? Es el caso, por ejemplo de los niños discapacitados en las escuelas de inserción, evidentemente van a necesitar más apoyo que sus compañeros (de modo distinto en función de que nos encontremos ante discapacitados físicos, psíquicos o sensoriales). Sin embargo, ese apoyo que precisan lejos de restar derechos a los demás consigue, mediante el ejercicio del derecho en cuestión, aproximar en mayor medida los rendimientos escolares de los primeros o la posibilidad de cursar estos estudios (en el caso de quienes cuentan con una movilidad reducida).

\section{Consecuencias del interés superior del niño}

La primera consecuencia que se extrae de la correcta aplicación del principio es la priorización del interés del niño sobre cualquier otro interés legítimo en presencia, tanto si ello supone considerar en menor medida este último como si se trata de no poder ponderarlo para resolver la situación en presencia (así lo establece la Ley Orgánica 1/1996, tras la modificación recientemente introducida en su artículo 2.4). Este efecto lo hemos comprobado en la jurisprudencia de la Corte Interamericana de Derechos Humanos como en la del Tribunal Europeo de Derechos Humanos.

El asunto Forneron e hija contra Argentina (recién visto en el epígrafe precedente) es un buen ejemplo del modo en el que puede afectar el interés superior del menor a cualquier otro en presencia. ${ }^{50}$ En este caso, la prevalencia del principio que nos ocupa nos puede abocar a soluciones aparen-

50 Es la Sentencia de la Corte Interamericana de Derechos Humanos, de 27 de abril de 2012, cuyo texto íntegro puede consultarse en: http://corteidh.or.cr/docs/casos/articulos/se riec_242_esp.pdf. 
Esta revista forma parte del acervo de la Biblioteca Jurídica Virtual del Instituto de Investigaciones Jurídicas de la UNAM

temente contradictorias con nuestro sentido de justicia, puesto que hemos de considerar cuál de ellas es la que beneficia en mayor medida el equilibrio psicológico y el desarrollo del niño.

El interés superior del menor no sólo se pondera en la jurisprudencia internacional, también en los tratados internacionales, pues es una excepción a la regla general aplicable, por ejemplo, en el caso de la sustracción internacional de menores. En este sentido, la Convención de La Haya sobre los Aspectos Civiles de la Sustracción Internacional de Niños, ${ }^{51}$ ejemplifica esta situación, pues declara que su propósito es "garantizar la restitución inmediata de los menores trasladados o retenidos de manera ilícita en cualquier Estado contratante", salvo que exista "un grave riesgo de que la restitución del menor lo exponga a un peligro grave físico o psíquico o que de cualquier otra manera ponga al menor en una situación intolerable”. ${ }^{2}$

El Tribunal Europeo de Derechos Humanos se pronunció sobre el caso de una pareja separada que, cuando la niña tiene dos años de edad, madre e hija abandonan clandestinamente el país de nacimiento y residencia hasta entonces (Israel) y se instalan en Suiza. Los tribunales suizos que conocen de la reclamación del padre conforme a la aplicación de la Convención de La Haya rechazan el retorno de la menor debido al grave riesgo psicológico que conllevaría. En este caso, el riesgo parece cierto pues debería separarse de su madre que podría permanecer en Suiza o regresar a Israel donde lo más probable sería su ingreso en prisión por el delito cometido. En consecuencia, el Tribunal Europeo de Derechos Humanos concluye (cuando la niña tiene 9 años) que ejecutar la orden de regreso del menor a Israel vulneraría el Convenio Europeo de Derechos Humanos. ${ }^{53}$

51 Es la Convención de La Haya de 1980, del que es parte España y está publicado oficialmente en el BOE núm. 202, de 24 de agosto de 1987, pp. 26099 y ss.

52 El mismo artículo $13 \mathrm{~b}$ contiene dos párrafos más que expresan respectivamente lo siguiente: «La autoridad judicial o administrativa podrá asimismo negarse a ordenar la restitución del menor si comprueba que el propio menor se opone a la restitución, cuando el menor haya alcanzado una edad y un grado de madurez en que resulte apropiado tener en cuenta sus opiniones. Al examinar las circunstancias a que se hace referencia en el presente artículo, las autoridades judiciales y administrativas tendrán en cuenta la información que sobre la situación social del menor proporcione la Autoridad Central u otra autoridad competente del lugar de residencia habitual del menor.»

53 En estos supuestos, resulta difícil establecer un equilibrio entre los intereses en causa, pues la aplicación del interés superior del menor nos conduce a consolidar una situación cuyo fundamento se encuentra en un comportamiento proscrito, cuál es la sustracción interna- 
Ese mismo interés se ha priorizado sobre el fraude de ley que eventualmente pueda encontrarse en el origen de la situación en presencia, es un supuesto al que tuvo que enfrentarse el Tribunal de Justicia de la Unión Europea en su jurisprudencia, aunque sin mencionar como fundamento de su decisión el interés superior del menor, sí que ha adoptado medidas tendentes a procurarlo, es el caso de la sentencia Ruiz Zambrano. ${ }^{54}$ En este supuesto son los hijos, de nacionalidad belga, los determinantes para procurar el permiso de residencia y trabajo a su progenitor, colombiano. La familia Ruiz Zambrano había llegado desde Colombia con un hijo, en territorio belga nacen los dos pequeños, a los que no inscriben como nacionales colombianos, y en su lugar, utilizan la ley belga que permite adquirir la nacionalidad de un recién nacido si ninguna de la de sus padres le proporciona este vínculo. Es cierto que en la sentencia no se refiere expresamente al interés superior del menor, pero resulta evidente el fundamento en la medida en que se plantea como alternativa a la solución finalmente aportada la expulsión de los progenitores, en cuyo caso los menores tendrían que salir del territorio del Estado del que son nacionales con el propósito de acompañarlos o en su defecto quedar bajo tutela de las instituciones protectoras de la infancia, separados de los padres.

También el interés superior del menor ha motivado cambios legislativos, ya se haya subrayado la necesidad por el Comité, la jurisprudencia de un tribunal internacional o la presión de la sociedad civil. Por ejemplo, desde las primeras observaciones generales del Comité sobre Marruecos se muestra su preocupación por el mantenimiento hasta enero de 2014 de la ley que permitía a un violador casarse con su víctima menor de edad para evitar la pena correspondiente al delito y limpiar el honor de la familia de la niña violada, con el fundamento del interés superior de la niña. La ley que, si bien condonaba la sanción del violador, perpetuaba el sufrimiento de la víctima, a cambio de no resultar ella y su familia estigmatizadas socialmente como consecuencia del delito del que había sido víctima (identificándose aquí el interés superior de la niña, que preconizaba la ley en cuestión).

cional de menores, beneficiando a quien incumple las normas. Aunque sabemos que ha de prevalecer el interés superior del menor, hay supuestos en los que el transcurso del tiempo unido a la búsqueda de ese interés aportan legalidad a una situación cuyo origen vulnera la legalidad vigente.

54 Es la STJUE del 8 de marzo de 2011, en el asunto C-34/09, Ruiz Zambrano/ Office national de l'emploi belge. 
Esta revista forma parte del acervo de la Biblioteca Jurídica Virtual del Instituto de Investigaciones Jurídicas de la UNAM

Esa preocupación del Comité, unida a la movilización en contra de este precepto legal se inició como consecuencia del suicidio de Amina Filali, de quince años, que protagonizó uno de estos matrimonios forzados por su familia. Pese a todo, en estas ocasiones dependemos de la coincidencia entre la preocupación del Comité y la movilización de la sociedad civil y de la voluntad del legislativo, que no siempre se produce. En todo caso, si bien esta lacra ha desaparecido en Marruecos, sigue vigente en países próximos, como Mauritania y en el mismo Estado marroquí, según la observación del Comité de 2014, el matrimonio infantil se mantiene por debajo de la edad establecida legalmente, permitiéndose mediante dispensa de la autoridad competente, en aras al interés superior del niño, que normalmente suele ser una niña.

Un ejemplo de modificación fruto de una sentencia del Tribunal Europeo de Derechos Humanos la encontramos en la consecuencia de las sentencias Menesson y Labassee contra Francia, ${ }^{55}$ en las que afirmaba que la legislación francesa que prohibía la inscripción registral de los niños nacidos en el extranjero mediante gestación subrogada vulnera el derecho a la vida privada, protegida en el artículo 8o. de la Convención Europea de Derechos Humanos. En todo caso, la actuación de los progenitores era contraria al ordenamiento nacional que prohibía este tipo de fecundación en Francia, aunque era la solución lógica si nos atenemos al interés superior de los niños recién nacidos.

\section{Conclusiones}

No podemos olvidar que los principales responsables del interés superior del menor son los padres y, cuando la situación trasciende del núcleo familiar, los órganos encargados en cada caso concreto de ellos, sean las autoridades tutelares que se encargan de ellos en defecto de contexto familiar, los jueces que deciden en conflictos que pueden afectar de algún modo a los menores, o el Poder Legislativo si es que se trata de adoptar normas que tengan real o potencialmente dentro de su alcance a los menores de edad.

55 Véase sentencias del Tribunal Europeo de Derechos Humanos del 26 de junio de 2014, Labassee c. Francia, en http://hudoc.echr.coe.int/sites/en/pages/search.aspx?i=001-145180 y Mennesson c. Francia, en http://hudoc.echr.coe.int/sites/fra/pages/search.aspx?i=001-145179. 
A lo largo de las páginas anteriores hemos advertido la flexibilidad característica del interés superior del menor, así como la relevancia de los criterios que sirvan para determinarlo en cada caso concreto, ubicando al menor en el centro de la decisión e intentando eliminar del juicio del órgano encargado de la aplicación normativa condicionamientos subjetivos que pudieran afectarle (morales, éticos o religiosos), lo que puede resultar el aspecto más difícil de su aplicación.

La correcta aplicación del bien superior del menor en aras a la estabilidad emocional del niño puede conducirnos a consolidar situaciones que tengan su origen en un fraude de ley o contrarias a ella, como en el caso de los secuestros internacionales. Sancionar con penas privativas de libertad al progenitor que ha trasladado sin consentimiento del otro o incluso ante su negativa y en ausencia de autorización judicial en caso de que ésta se requiera, en la medida en que sería contraria al bien superior del menor, consolida la guardia y custodia de quien ha vulnerado las normas, pero sólo atendiendo a este interés prioritario a los demás. A pesar de ello, hemos de considerar que en estos supuestos probablemente ambos persiguen el interés del hijo en común, aunque cada uno desde su propia perspectiva.

Por tanto, no siempre la aplicación del principio conduce a soluciones objetivamente justas, bien al contrario, podría llevarnos a que esta protección vulnera los derechos reconocidos a otros o a resultados que parecen alejados del derecho, porque son soluciones que, de no existir un menor, resolveríamos de un modo diametralmente contrario o alejado del que cuenta con un niño a proteger. Pero nos encontramos precisamente en un contexto de protección del menor. Esa es precisamente la esencia de este principio.

Sin embargo, con todos los riesgos que puedan derivar de la aplicación del bien superior del menor, siempre resulta más conveniente y convincente su consideración para evitar las situaciones a las que nos aboca su inobservancia. Recordemos el caso del niño de El Royo, un bebé que vivía en el seno de una familia en acogida y fue separado de ellos debido a una decisión judicial que supuso su internamiento en un centro de acogida con el propósito de estar cerca de su madre, porque su cercanía sería una terapia que repercutiría positivamente en la salud de su progenitora. En estos años no sabemos si ciertamente la salud de la madre evolucionó positivamente, lo que es sobradamente conocido es que desde entonces la vida del menor ha sido una secuencia de ingresos sucesivos en centros de acogida y todo 
Esta revista forma parte del acervo de la Biblioteca Jurídica Virtual del Instituto de Investigaciones Jurídicas de la UNAM

debido a la ausencia de ponderación del interés del menor. Evidentemente, el interés del menor habría indicado su permanencia en un hogar estable, como era el de acogida, en el que se encontraba.

En consecuencia, lo anterior indica que es mejor equivocarse sobrevalorando el interés del menor que incurrir en errores cuyos efectos no tienen solución. A pesar de la inseguridad que la evaluación de los intereses en presencia y de alcanzar, en ocasiones, decisiones contrarias a nuestro sentido de justicia, considerar el interés del menor como prioritario a otros, además de ser una obligación legal, es una apuesta de futuro. Lo que no quita para que la consideración y el estudio de la jurisprudencia que ha aplicado este criterio nos deje en ocasiones una sensación agridulce.

\section{BIBLIOGRAFÍA}

Aldecoa luzárraga, F. y Forner Delaygua, J. J. (dirs.), La protección de los niños en el derecho internacional y en las relaciones internacionales, Madrid, Marcial Pons, 2010.

Carmona LuQue, M. R., La Convención sobre los derechos del niño. Instrumento de progresividad en el Derecho Internacional de los Derechos Humanos, Madrid, Dykinson, 2011.

De Bartolomé Cenzano, J. C., "Sobre la interpretación del interés superior del menor y su trascendencia en el derecho positivo español”, Revista sobre la Infancia y la Adolescencia, núm. 3, septiembre de 2012.

García-Mendez, E. y Beloff, M. (comps.), Infancia, ley y democracia en América Latina, Buenos Aires, Temis-Depalma, 1998.

GonzÁlez Martín, N. y RodrígueZ JiméneZ, S., El interés superior del menor en el marco de la adopción y el tráfico internacional. Contexto mexicano, México, UNAM, Instituto de Investigaciones Jurídicas, 2011.

Hierro, Liborio L., “¿Tienen los niños derechos? Comentario a la Convención sobre los Derechos del niño”, Revista de Educación, núm. 294, 1991. InVERnizZI, A. y Williams, J. (eds.), The Human Rights of Children, Ashgate, Surrey, 2013.

Laing Klaff, R., “The Tender Years Doctrine: a Defense”, California Law Review, vol. 70-2, 1988. 
Esta revista forma parte del acervo de la Biblioteca Jurídica Virtual del Instituto de Investigaciones Jurídicas de la UNAM

MACÍAS VÁZQUEZ, M. C. et al., Marco teórico conceptual: violencia contra niños, niñas y adolescentes, México, UNAM, Instituto de Investigaciones Jurídicas, 2013.

POCAR, F. "La protection de la partie faible en Droit International Privé", Recueil de Cours de l'Académie de Droit International, 188 (1984)-V.

RODRÍGUEZ Llamas, S., "La atribución de la guarda y custodia en función del concreto y no abstracto interés superior del menor. Comentario a la STS núm. 679/2013, de 20 de noviembre (RJ 2013/7824)”, Revista Boliviana de Derecho, núm. 19, enero de 2015.

VARGas GómeZ-URRuTia, M., La protección internacional de los derechos del niño, Secretaría de Cultura, Gobierno de Jalisco, 1999.

Verdugo, M.A. y Soler-Sala, V. (eds.), La Convención de los Derechos del Niño hacia el siglo XXI, Salamanca, Ediciones Universidad, 1996. 